\title{
Standbein - Spielbein
}

_ Neulich haben wir einen Leserbrief bekommen ( $\odot$ S. 6), der mich nachdenklich machte. Wir Physiotherapeuten hauen uns zurzeit - so auch meine Wahrnehmung - permanent gute Ideen für ein zweites Standbein um die Ohren, beispielsweise die Eroberung neuer Geschäftsfelder für Selbstzahler. Die Ursache dafür ist klar: der miserable Verdienst. Doch müssen wir uns dafür wirklich nach neuen Spielwiesen umschauen?

- Wie der Kollege Peter Schlaps bin ich der Meinung: Nein, das müssen wir nicht. Unser Standbein ist die Physiotherapie, ein Beruf mit vielfältigen Möglichkeiten. Wenn wir einen Schritt in Felder tun wollen, in denen physiotherapeutisches Know-how wichtig wäre

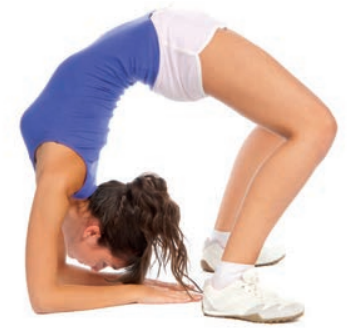

Wir wollen Ihnen Perspektiven zeigen, Sie aber nicht verbiegen. oder gar gefragt ist, müssen wir nicht unseren Standpunkt verändern. Aber wir müssen unser Gewicht verlagern und das Spielbein aktivieren. Denn es gibt Felder, für die wir zwar über ausreichende Expertise verfügen, sie aber nicht ausreichend besetzen. Beispiele sind betriebliche Gesundheitsförderung oder die geriatrische Reha.

_ Wer das Angebot seiner Praxis erweitern will, fragt sich: Was passt zu mir mit meiner Qualifikation und welche Weiterbildung bietet sich speziell für mich an, um mein Tätigkeits- oder Angebotsportfolio zu vergrößern? Auf diese Fragen geben die im Leserbrief angesprochenen Artikel in praxisprofi Antworten. Wir wollen anregen und Ihnen passende Tätigkeitsfelder vorstellen, aber Sie ganz sicher nicht verbiegen. Physiotherapeuten haben Zukunft!

Herzlichst, Ihre

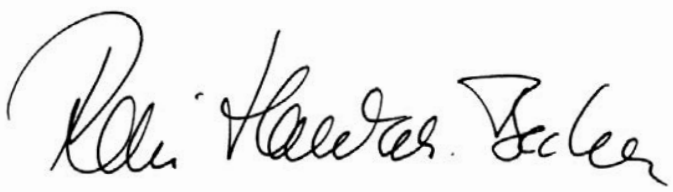

PS: Freuen Sie sich auf eine neue Gestaltung des praxisprofi ab 2014. Wir haben zusammen mit Herausgeberin Anna von Eisenhart Rothe ein neues und, wie wir denken, noch attraktiveres Konzept gestrickt. Lassen Sie sich überraschen. 